\title{
Hearing from men in South Africa: Shifts in HIV risk and service uptake-Findings from DREAMS implementation science research
}

Population Council

Follow this and additional works at: https://knowledgecommons.popcouncil.org/departments_sbsr-hiv How does access to this work benefit you? Let us know!

\section{Recommended Citation}

Population Council. 2021. "Hearing from men in South Africa: Shifts in HIV risk and service uptake-Findings from DREAMS implementation science research," DREAMS Results Brief. Washington, DC: Population Council. 


\section{HEARING FROM MEN IN SOUTH AFRICA: SHIFTS IN HIV RISK AND SERVICE UPTAKE}

FINDINGS FROM DREAMS IMPLEMENTATION SCIENCE RESEARCH

HIV prevention efforts across sub-Saharan Africa are increasingly focused on engaging men, for their own health and that of their partners and families. We examined whether and how HIV risk and protective factors are changing among men in Durban, South Africa-a country with a substantial HIV burden. The study is part of the Population Council's implementation science research portfolio on the DREAMS Partnership ${ }^{1}$, a large-scale initiative to reduce new HIV infections among adolescent girls and young women (AGYW) and their partners. Our studies related to male partners of AGYW were carried out in Eswatini, South Africa, and Uganda.

Engaging men/male partners is key to addressing AGYW's risk, and DREAMS aims to do so by getting men/male partners of AGYW into HIV testing, voluntary medical male circumcision (VMMC), linkage to HIV care and antiretroviral treatment (ART), and implementing programming to change harmful gender norms in communities, including among men/male partners. In this study we sought to:

- Identify successes and challenges of linking men to HIV services.

- Assess shifts in men's HIV risk factors over time.

- Assess exposure to and effects of USAID/PEPFARrelated activities, for men.

Location: Two informal settlements in Ethekwini (Durban), South Africa

Study Duration: 2016-2019

Funder: Bill \& Melinda Gates Foundation

This research was conducted in close collaboration with: Epicentre Health Research, Government of South Africa Department of Health, and South Africa National AIDS Council

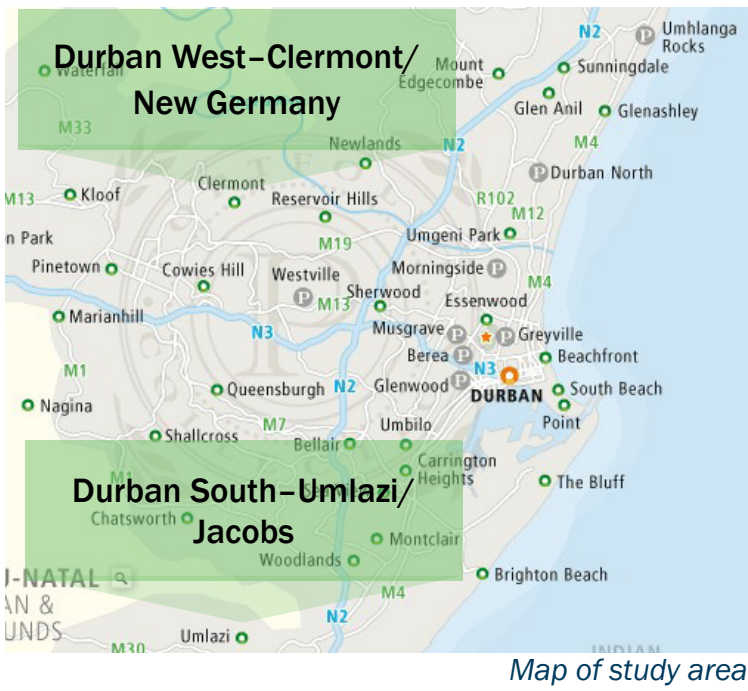

\section{KEY FINDINGS}

Between 2017 and 2018 ( 1 year time-span), there were promising reductions in several HIV risk factors (numbers of sexual partners, hazardous drinking, intimate partner violence, and endorsement of inequitable gender norms).

Improvements in HIV service use were more mixed, with increases in current use of antiretroviral treatment (among men living with HIV) as well as awareness of treatment as prevention (TasP), but no increases in HIV testing or circumcision (status).

Despite respondents' elevated HIV-related risk (even after reductions), there was also minimal exposure to community-based HIV prevention programming at each round.

Men who were exposed to HIV prevention programming, felt that it supported them to reduce their number of sexual partners, improve relationship dynamics, and HIV service engagement. 


\section{METHODS}

We conducted two cross-sectional surveys with men ages 20-40 (the DREAMS target age range for men/ male partners of AGYW in that country) in two informal settlements in Ethekwini (Durban). This included 876 men at Round 1 (May-September 2017) and 789 men at Round 2 (June-August 2018) who reported at least one sexual partner in the last year. About twothirds of respondents were recruited from hot-spot venues across districts where intensive combinationprevention programs, including DREAMS, were taking place. These hot spot venues were identified by key informants as places where men at potentially higher risk of HIV infection congregate and where they meet AGYW and form relationships. ${ }^{2}$ The remaining one-third respondents recruited at community- and facilitybased HIV service sites to help capture experiences of men who used HIV services.

We assessed changes over time in key HIV risk behaviors, service use, and program exposure among the men, controlling for age, marital status, employment status, and type of recruitment site, and accounted for the clustered survey design.

Surveys were complemented by 48 qualitative indepth interviews in 2018 with male partners of AGYW who had recently participated in HIV services and/or HIV prevention programming, including a subsample of men living with HIV. These men were recruited via DREAMS implementing partners or based on their Round 2 survey responses (i.e., reported HIV service/ program participation and/or living with HIV). Thematic data analyses followed a team-based, iterative process to arrive at final themes.

\section{Who were the survey respondents?}

(largely similar across the 2 rounds)

Mean age: 28;

28 years $(27.6 \% \mathrm{R} 1,28.7 \% \mathrm{R} 2$, $\mathrm{p}<0.001)$

\section{$15 \%$ were married or cohabiting}

$57 \%$ employed (54\% R1, 59\% R2, p<0.05)

Three-quarters had completed at least secondary school
Among the 48 in-depth interview participants, mean age was 26 years (range $20-40$ ). Less than $15 \%$ of men were married/cohabiting. About one-quarter were HIV-positive.

\section{CHANGE IN HIV SERVICE USE}

\section{HIV testing, circumcision, and antiretroviral treatment increased}

HIV testing in the last year

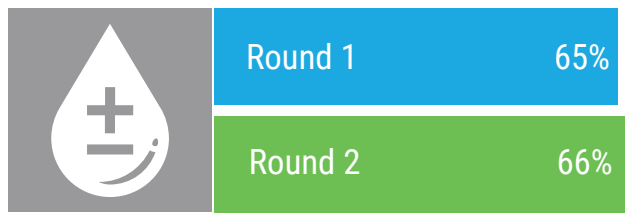

Adjusted odds ratio $1.04(95 \% \mathrm{Cl} 0.81,1.33)$, nonsignificant (assessed among venue-based sample only ( $n=582$ at R1, 478 at R2), since service-based sample included many coming for HIV testing)

Circumcised (status)

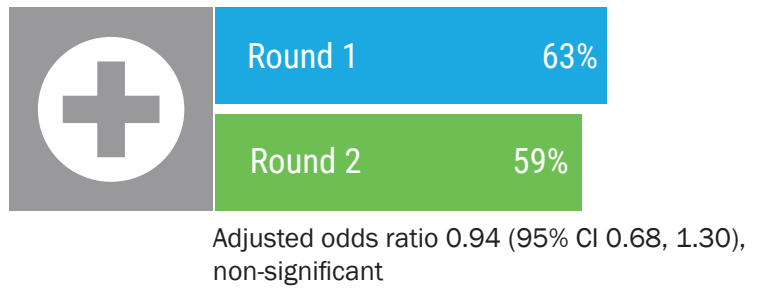

Currently taking ART (men living with HIV)

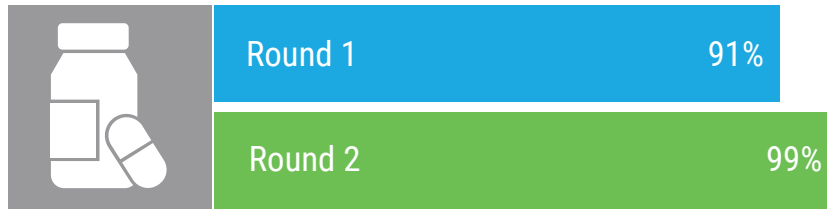

R1 n=69 and R2 n=133 of men living with HIV; Adjusted odds ratio $2.16(95 \% \mathrm{Cl} 1.60,2.92)$, $p<0.001$

Aware that HIV treatment can prevent onward transmission

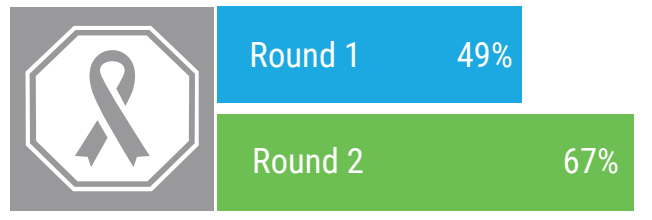

Adjusted odds ratio $2.16(95 \% \mathrm{Cl} 1.60,2.92)$, $\mathrm{p}<0.001$; Responded "yes" to "Can taking ART reduce the risk of transmitting the HIV/AIDS virus to another person?") 


\section{Convenient options facilitated routine HIV service}

use. Men who participated in in-depth interviews described increasingly convenient and varied options for HIV testing, VMMC, and ART now available. For example, along with facility-based testing, there were mobile, door-to-door, workplace, and self-testing options.

There are now mobile clinics...like the way they do things recently, you would say to do testing is the important thing now.

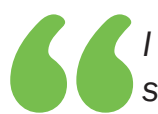

I got the [self-test] from the college.... lady standing at the main gate.... I thought I should do it because it had been a while since I last did HIV testing. [Testing negative] was a relief, so from then I had to make sure that I protect myself.

-Age 20

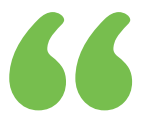
Here in [my neighborhood], there are NGOs working with care workers who bring medication to the homes of those living with HIV. Men have pride and do not want to be seen queuing for treatment at government clinics. So, these care workers they ensure that the medication gets to these men and is taken.... There are [also] group or associations formed where men living with HIV.... They get to share with these counsellors every issue they may have with their treatment without having to go to the clinics.

\section{Supportive messaging about the effectiveness of} early HIV diagnosis and treatment was critical. This information/messaging was often communicated to men during pre-HIV test counseling and was consistently described as easing men's fears around testing for HIV and subsequently linking to care if HIV-positive.

\footnotetext{
The way they test you and the way they talk with you if you are HIV positive... [they] give you certain comfort plans and tell you that it is not the end of the world and you can live for more than forty years if you follow certain rules, you will live your life to the fullest.
}

I have lived in many places [and] had girlfriends in all these areas.... What made me to test [last year] was that all my friends encouraged me...they are all positive. And they were saying this thing is better now than before... take one tablet and you are fine. [separate segment] I was testing for the first time...[although] I suspect I got infected 18 years ago, [when] this thing [HIV] was still scary. [separate segment] [The counselor] explained that you are the same with any other person who is not infected. The more you care for yourself and eat your treatment well, is the more you get better, you will feel like you are not sick.

-Age 40, HIV-positive

\section{Treatment literacy was suboptimal.}

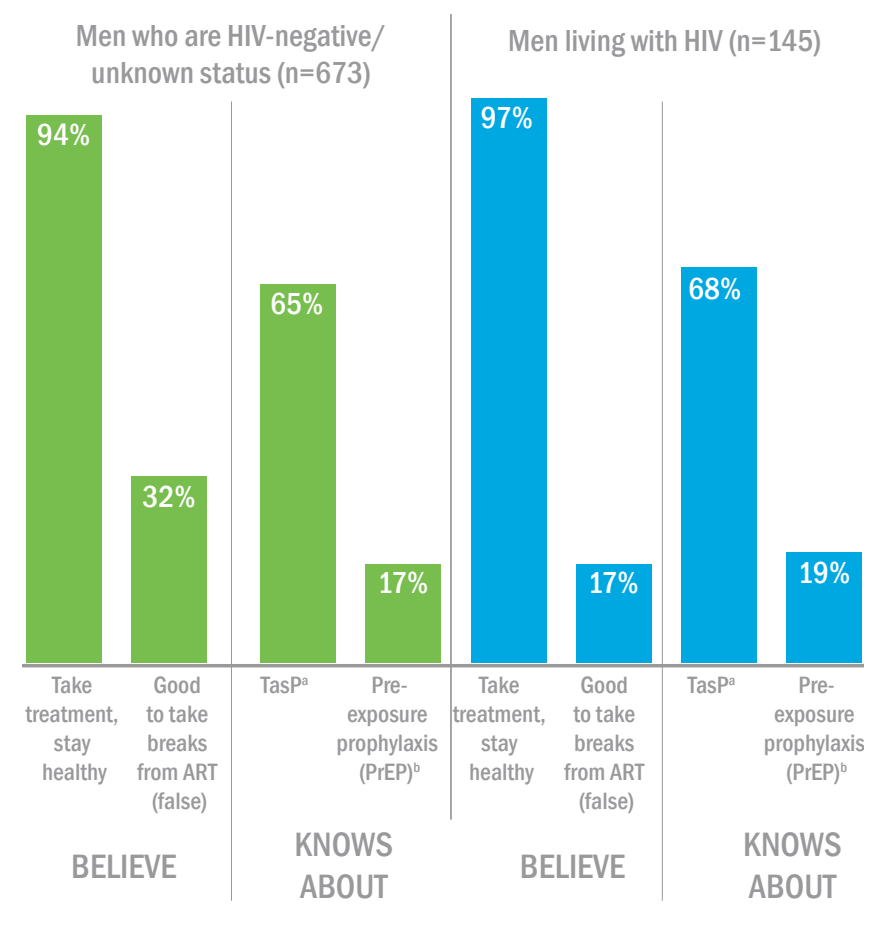

aResponded "yes" to "Can taking ART reduce the risk of transmitting the HIV/AIDS virus to another person?"

"Responded "yes" to "Are there any special drugs an HIV-negative person can take to help avoid getting the virus from an HIV-positive partner?"

Data shown are from the Round 2 survey. 


\section{CHANGE IN HIV-RELATED RISK BEHAVIORS}

\section{Men reported substantial reductions} in numbers of sexual partners between Rounds 1 and 2.

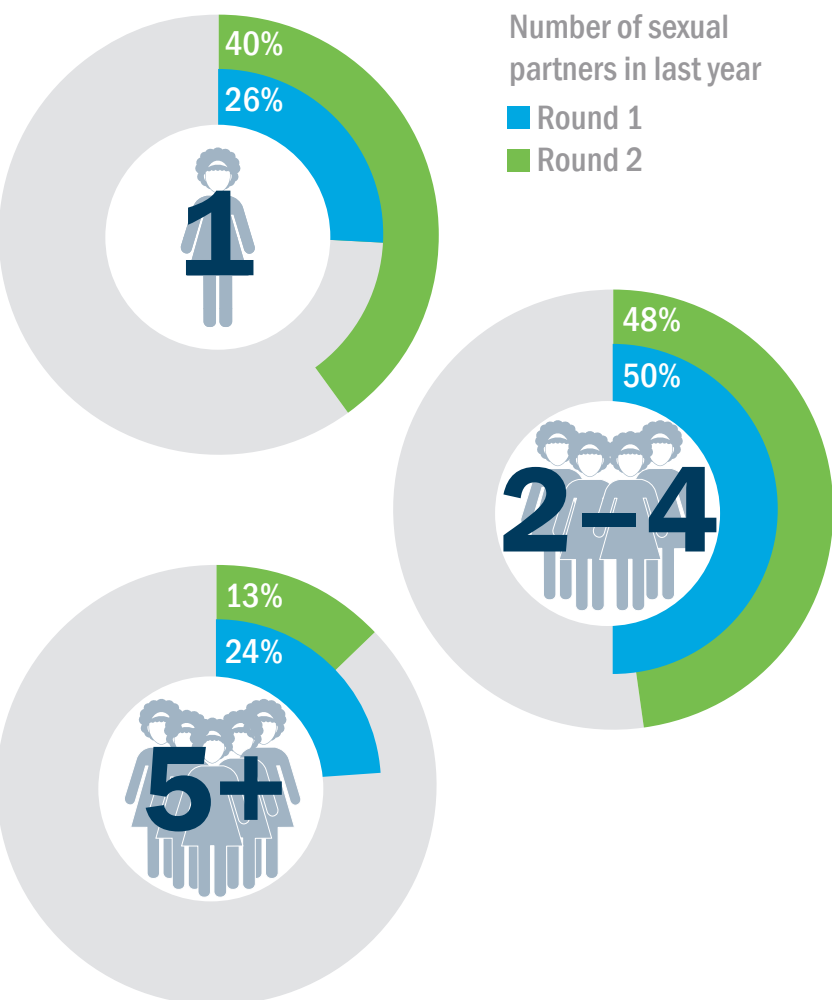

Adjusted odds ratio from ordinal logistic regression: 0.53 (95\% $\mathrm{Cl} 0.42$, $0.67), p<0.001$

There were also reductions in hazardous drinking, endorsement of inequitable gender norms, and intimate partner violence perpetration.

\begin{tabular}{|c|c|c|c|}
\hline & $\begin{array}{c}\mathrm{R} 1 \\
\%\end{array}$ & $\begin{array}{c}\mathrm{R} 2 \\
\%\end{array}$ & aOR \\
\hline Hazardous drinkinga & 52 & 43 & $\begin{array}{l}0.70^{* *} \\
(0.55 \\
0.88)\end{array}$ \\
\hline $\begin{array}{l}\text { Endorsement of highly } \\
\text { inequitable gender norms }\end{array}$ & 25 & 13 & $\begin{array}{l}0.47^{* * *} \\
(0.35 \\
0.62)\end{array}$ \\
\hline $\begin{array}{l}\text { Intimate partner violence } \\
\text { perpetration (with any of } \\
\text { last } 3 \text { partners) }\end{array}$ & $\begin{array}{c}20 \\
(n=875)\end{array}$ & $\begin{array}{c}16 \\
(n=785)\end{array}$ & $\begin{array}{c}0.76^{*} \\
(0.59 \\
0.97)\end{array}$ \\
\hline
\end{tabular}

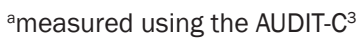

${ }^{b}$ measured using the GEM scale ${ }^{4}$, dichotomized at the mid-point

${ }^{*} p<0.05 ; * * p<0.01 ; * * * p<0.001$
Transactional relationships were common and did not significantly change over time.

\begin{tabular}{|lcc|} 
& R1 & R2 \\
\hline None & $\%$ & $\%$ \\
Less resource-intensive & 44 & 53 \\
More resource-intensive & 44 & 33 \\
\hline
\end{tabular}

Based on reporting giving at least one item or service 'mainly so you could start or stay in a sexual relationship' with a partner, in the last year ${ }^{5}$ ). Examples of less resource-intensive transactions: buying clothes, food, cell phones. Examples of more resource-intensive transactions: paying for their partners' school fees or place to live.

There were also no changes in consistent condom use or age disparity with partners

Consistent condom use with last 3 non-marital/non-cohabiting partners

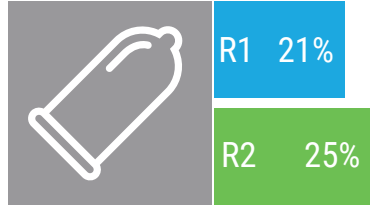

Adjusted odds ratio 1.29 (95\% Cl 0.98, 1.70) non-significant)

Age disparity with last 3 non-marital/non-cohabiting partners

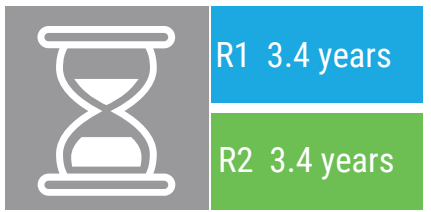

Adjusted Beta: $-0.30(-0.53$ -0.06), non-significant)

\section{MEN'S EXPOSURE TO AND PERCEPTIONS OF HIV PREVENTION PROGRAMMING}

\section{HIV program exposure was low.}

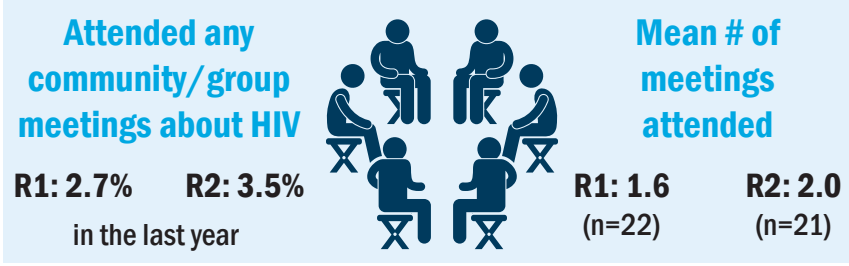

These low reported levels of participation in HIV prevention meetings in surveys precluded meaningful assessments of associations with HIV risk factors/ service use. 


\section{HIV prevention programming was eagerly received by men and supported positive behavior change.}

Our qualitative research helped elucidate the experiences of the minority of men who participated in HIV prevention programming. Men consistently described welcoming the opportunity to do participate in such programming. Commonly reported effects of prevention programs on men's HIV risk factors were reductions in numbers of sexual partners, improved communication and reduced violence in relationships. Such programming also provided a foundation of information and support that facilitated engagement in HIV services particularly among those formerly reluctant to do so.

We talked about various topics...[like] about ways to keep relationships alive and happy. Here we were told that we need to stay away from this "men must control everything" attitude because it brings gender-based violence in our communities... These meetings are like information hubs...[like] l've learned that one must always have their [HIV] status checked because it is better to know.

-Age 24

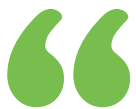

...we are always out at night...[and] you find yourself having sex outside the bar...you see I stay at [__ ] , so those things are happening around here. [Separate segment] [Stepping Stones] was for both men and women...l like the fact that we were all communicating. We are from the same community and that class helped because some people we did not know that much ...but we were able to get to know each other and understand each other... It influenced me a lot... They helped us that we should know our status, so that you can work and in your relationship. There is nothing you cannot mend.

People who have stressed the importance of testing for HIV are your 'Stepping Stones' crew...We discussed many topics around disease and health awareness...[and] I like the fact that these meetings teach us about way we can live in diverse community harmony...It has opened my mind up to many things, I now appreciate and know the significance of these services, like VMMC...
Men who participated in mixed-gender groups also often described how this helped men and women get to know each other and understand each other.

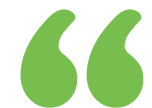
It was for both men and women...I like the fact that we were all communicating. We are from the same community and that class helped because some people we did not know that much ...but we were able to get to know each other and understand each other... It influenced me a lot... They helped us that we should know our status, so that you can work and in your relationship. There is nothing you cannot mend.

In addition to, or more commonly instead of, participating in mixed gender sessions, many men described participating in "Men to Men", several brief HIV prevention sessions held only/mainly with men. These meetings were described as providing opportunities for men to discuss the life challenges they face and learn positive coping strategies, in addition to encouraging HIV risk reduction and linkage to services. This was particularly the case for men at higher risk and/or those reluctant to join sessions they anticipated would be dominated by women.

\section{The 'Men to Men' program is there to} listen, share and provide coping skills for these issues men are facing. So, we learn a lot, we share our daily struggles with our peers. The more we hear each other struggles, the more we realize that we are not alone... We [also] discuss many topics like discipline, love, relationship and health issues, all of which are aimed at men.

[We] share experiences, defeats and triumphs everyone has encountered. I think this is done to give each other tips on how to get through life. Also, we will be chatting to each other about diseases young people, suffer with and how these can be cured or treated.

\section{RECOMMENDATIONS}

- Given high levels of multiple HIV risk factors-even accounting for reductions over time-scaling up HIV prevention programming for men is imperative.

- To be most successful, activities should include critical reflection about gender roles and HIV risk. 
Evidence suggests that such programs should last beyond a few sessions, and engage both men and women (together and in separate groups). ${ }^{6,7}$

- Implement supportive prevention programming that invites and meaningfully engages men $^{8}$, including in opportunities to discuss life challenges with other men, for supporting uptake of services for hard-toreach men.

- Complement facility-based services for men with a continued emphasis on community-based, clientcentered services.

- Prioritize information and messaging around HIV treatment efficacy, including PrEP and TasP/ Undetectable $=$ Untransmittable $(\mathrm{U}=\mathrm{U})$, as part of promoting men's informed decision-making about their own health and preventing transmission to their partners. ${ }^{9,10}$

- Take into account, and build on, broad social/ contextual shifts underway. Recent research in South Africa suggested that similar reductions in risk factors to those found in this study may be due to rapidly expanding media access (TV/satellite dish and smartphones) ${ }^{11}$, which is exposing more people to equitable gender norms, modeling more equitable communication in relationships, and also potentially changing time-use patterns.

\section{REFERENCES}

${ }^{1}$ Saul, J. et al. 2018. “The DREAMS core package of interventions: A comprehensive approach to preventing HIV among adolescent girls and young women," PLoS ONE 13(12): e0208167. doi: 10.1371/journal.pone.0208167

${ }^{2}$ Reynolds, Z. et al. 2018. "Who are the male partners of adolescent girls and young women in Swaziland? Analysis of survey data from community venues across 19 DREAMS districts," PLoS ONE 13(9): e0203208. doi: 10.1371/journal. pone.0203208

${ }^{3}$ Bush, K. et al. 1998. "The AUDIT alcohol consumption questions (AUDIT-C): an effective brief screening test for problem drinking," Archives of Internal Medicine 158(16): 1789-1795. doi: 10.1001/archinte.158.16.1789

${ }^{4}$ Pulerwitz, J. and G. Barker. 2008. "Measuring attitudes toward gender norms among young men in Brazil," Men and Masculinities 10: 322-338. doi: 10.1177/1097184X06298778

${ }^{5}$ Stoebenau, K. et al. 2016. "Revisiting the understanding of 'transactional sex' in sub-Saharan Africa: a review and synthesis of the literature," Social Science \& Medicine 168: 186-197. doi: 10.1016/j.socscimed.2016.09.023

${ }^{6}$ Ruane-McAteer, E. et al. 2020. “Gender transformative programming with men and boys to improve sexual and reproductive health and rights: A systematic review of intervention studies," BMJ Global Health 5(10): e002997. doi:10.1136/ bmjgh-2020-002997

\section{For more information about the DREAMS IS portfolio:}

Visit the DREAMS IS special series page: https:// knowledgecommons.popcouncil.org/series_dreams/

"How to reduce HIV risk among adolescent girls and young women in sub-Saharan Africa? Implementation science around the DREAMS Initiative," DREAMS Project Brief. doi: 10.31899/hiv7.1009

"Reducing HIV risk among young women and their partners: highlights from the DREAMS implementation science research portfolio," DREAMS Project Brief. doi: 10.31899/hiv11.1026

For more information about the study in South Africa:

"Effective engagement of male partners of adolescent girls and young women in South Africa: Implementation science research in South Africa," Activity Brief. doi: 10.31899/hiv6.1011

"Male partners of adolescent girls and young women: relationship characteristics and HIV risk-findings from DREAMS implementation science research," DREAMS Results Brief. doi: 10.31899/hiv5.1015

"Creating HIV risk profiles for men in South Africa: A latent class approach using cross-sectional survey data," Journal of the International AIDS Society 23(S2): e25518 doi: 10.1002/jia2.25518

\section{Study contacts:}

Ann Gottert (agottert@popcouncil.org) and Julie Pulerwitz (jpulerwitz@popcouncil.org)

${ }^{7}$ Dworkin, S. L., S. Treves-Kagan, S. A. Lippman. 2013. “Gender-transformative interventions to reduce HIV risks and violence with heterosexually-active men: a review of the global evidence," AIDS and Behavior 17(9): 2845-63. doi: 10.1007/ s10461-013-0565-2

8Pulerwitz, J. et al. 2019. “Do's and don'ts for engaging men \& boys." Washington, D.C.: IGWG.

${ }^{9}$ Lippman, S. A. et al. 2020. "Treatment as prevention-provider knowledge and counseling lag behind global campaigns," Journal of Acquired Immune Deficiency Syndromes 83(2): e9-e12. doi: 10.1097/QAl.0000000000002197

${ }^{10}$ Mooney, A. C. et al. 2017. “Men's perceptions of treatment as prevention in South Africa: Implications for engagement in HIV care and treatment," AIDS Education and Prevention 29(3): 274-87. doi: 10.1521/aeap.2017.29.3.274

${ }^{11}$ Gottert, A. et al. 2020. "Gaining traction: Promising shifts in gender norms and intimate partner violence during an HIV prevention trial in South Africa," PLOS ONE 15(8): e0237084. doi: 10.1371/journal.pone.0237084

\section{POPULATION} COUNCIL

Ideas. Evidence. Impact.
The Population Council confronts critical health and development issues-from stopping the spread of HIV to improving reproductive health and ensuring that young people lead full and productive lives. Through biomedical, social science and public health research in about 50 countries, the Council works with our partners to deliver solutions that lead to more effective policies, programs, and technologies to improve lives worldwide. Established in 1952 and headquartered in New York, the Council is a nongovernmental, nonprofit organization with an international board of trustees. popcouncil.org

Suggested citation: Population Council. 2021. "Hearing from men in South Africa: Shifts in HIV risk and service uptake-findings from DREAMS implementation science research," South Africa DREAMS Results Brief. Washington, DC: Population Council. 